\title{
Metode Contextual Teaching and Learning (CTL) \\ Pada Pembelajaran BE GOING TO vs WILL di SMK NEGERI 2 MANADO
}

\author{
Agnes B.B. Mamiasa \\ Agnesbetsy82@gmail.com \\ Maya P.Warouw \\ Jenny H.Pakasi \\ Pascasarjana \\ Universitas Sam Ratulangi
}

\begin{abstract}
Contextual Teaching and Learning Approach (CTL) is one form of approach that can be said to be capable and very suitable to be a model of appropriate learning when applying the form of material in the classroom. Learning the form of CTL is closely related to the context, atmosphere or circumstances that can be interpreted also as learning related to a particular atmosphere. Talking about the atmosphere has to do with the use of the time form also known as tense. A little interesting about the Simple Future Tense that is raised to the core of learning because of this Tense became one of the important parts in the use of Grammar on learning English where we can express or declare actions in the future. This form uses the word 'will' and 'shall' (short form: 'll) plus infinitive. Besides using the form of 'going to' to be able to declare the time to come and the intention of the speaker to do something, for example I'm going to stop smoking '. CTL's role can make learning more effective and even create a fun and non-boring atmosphere, providing experiences that are closely related to the real world of learners and using a variety of learning resources; and therefore the method on CTL can provide understanding, development of science, the develop of knowledge and contextual understanding of learners about the relationship of subjects with what found learners in everyday life.
\end{abstract}

Keywords : CTL, BE GOING TO vs WILL

\section{Pendahuluan}

Perubahan model pandangan dalam paradigma system pembelajaran dari teacher centre ke student centreyang pada dasarnya mendorong cara pandang 
dengan perubahan gaya mengajar yang lebih menekankan kepada keaktifan peserta didik. Dapat dilihat betapa besarnya peran pendidikan dalam proses pengembangan baik dari segi karakter dan skill dari peserta didik.Pendidikan adalah usaha sadar untuk menyiapkan peserta didik melalui kegiatan bimbingan, pengajaran dan pelatihan bagi perannya di masa yang akan datang ( UU No. 2 Tahun 1989 ). Kalau melihat system dan model pembelajaran yang lama sangat dititik beratkan pada konsep dan cara pandang bahwa guru adalah satu - satunya pusat belajar yang juga menanamkan pemikiran baku bagi peserta didik untuk menjadikannya sebagai referensi sebagai pedoman dan contoh. Dan memang Guru ataupun pengajar adalah pola panutan yang patut dicontohi bagi peserta didiknya, tetapi guru juga adalah pribadi yang memiliki keterbatasan, lebihnya lagi ketika membagikan metode bentuk pembelajaran bagi peserta didiknya, yang dalam artian keterbatasan dalam ilmu pengetahuan, pengelolaan kelas dan keterbatasan dalam memahami karakter masing - masing peserta didik yang dibinanya, bahkan masih banyak lagi bentuk keterbatasan yang lain dan dapat menjadi permasalahan yang ditemui di lapangan, mengingat perkembangan di dunia pendidikanpun mengalami perubahan seiring dengan perkembangan zaman di mana pola pikir pendidik harus berubah dari konservatif ( system ajar yang tradisional ) untuk menjadi ke yang lebih modern.

Dari keterbatasan itulah selalu menjadi momok utama bagi pengajar ketika mencoba mengembangkan system pendekatan atau model pembelajaran yang dapat dikatakan tepat bagi peserta didik. Salah satu metode pembelajaran yang mampu menciptakan suasana yang menyenangkan dan tidak membosankan, dan yang menggunakan berbagai macam sumber belajar dan memberikan pengalaman pada dunia nyata ( real world learning ) yaitu metode Contextual Teaching and Learning ( CTL ) atau Pembelajaran Kontekstual. CTL disebut pembelajaran yang Kontekstual karena konsep belajarnya yang membantu guru / pengajar untuk mengaitkan antara materi yang diajarkannya dengan situasi dunia nyata peserta didik dan mendorong peserta didik sendiri untuk membuat hubungan antara pengetahuan yang dimilikinya dengan penerapannya dalam kehidupan mereka sebagai bagian dari masyarakat. Menurut Nurhadi dalam Sugianto (2007) CTL ( Contextual Teaching and Learning ) adalah konsep belajar yang 
mendorong guru untuk menghubungkan antara materi yang diajarkan dan situasi dunia nyata siswa. Sedangkan menurut Jonhson dalam Sugiyanto (2007) CTLadalah sebuah proses pendidikan yang bertujuan untuk menolong para siswa melihat makna didalam materi akademik yang mereka pelajari dengan cara menghubungkan subyek-subyek akademik dengan konteks dalam kehidupan keseharian mereka.

Pendekatan CTL sangatlah membantu pada pembelajaran bentuk BE GOING TO dan WILL dengan mempermudah bagi pengajar dan peserta didik untuk dapat mentransfer dan menerima materi ini. Di mana CTL sendiri memiliki tujuh komponen pembelajaran yang efektif yang meliputi :

1. Konstruktivisme, konsep ini yang menuntut siswa untuk menyusun dan membangun makna atas pengalaman baru yang didasarkan pada pengetahuan tertentu. Pengetahuan dibangun oleh manusia sedikit demi sedikit, hasilnya diperluas melalui konteks yang terbatas dan tidak secara tiba-tiba. Strategi pemerolehan pengetahuan lebih diutamakan dibandingkan dengan seberapa banyak siswa mendapatkan dari atau mengingat pengetahuan.

2. Tanya jawab,dalam konsep ini kegiatan tanya jawab yang dilakukan baik oleh guru maupun oleh siswa. Pertanyaan guru digunakan untuk memberikan kesempatan kepada siswa untuk berpikir secara kritis dan mengevaluasi cara berpikir siswa, seangkan pertanyaan siswa merupakan wujud keingintahuan. Tanya jawab dapat diterapkan antara siswa dengan siswa, guru dengan siswa, siswa dengan guru, atau siswa dengan orang lain yang didatangkan ke kelas.

3. Inquiry, merupakan siklus proses dalam membangun pengetahuan/ konsep yang bermula dari melakukan observasi, bertanya, investigasi, analisis, kemudian membangun teori atau konsep. Siklus inkuiri meliputi; 
observasi, tanya jawab, hipoteis, pengumpulan data, analisis data, kemudian disimpulkan.

4. Komunitas Belajar, adalah kelompok belajar atau komunitas yang berfungsi sebagai wadah komunikasi untuk berbagi pengalaman dan gagasan. Prakteknya dapat berwujud dalam; pembentukan kelompok kecil atau kelompok besar serta mendatangkan ahli ke kelas, bekerja dengan kelas sederajat, bekerja dengan kelas di atasnya, bekerja dengan masyarakat.

5. Pemodelan, dalam konsep ini kegiatan mendemontrasikan suatu kinerja agar siswa dapat mencontoh, belajar atau melakukan sesuatu sesuai dengan model yang diberikan. Guru memberi model tentang how to learn (cara belajar) dan guru bukan satu-satunya model dapat diambil dari siswa berprestasi atau melalui media cetak dan elektronik.

6. Refleksi, yaitu melihat kembali atau merespon suatu kejadian, kegiatan dan pengalaman yang bertujuan untuk mengidentifikasi hal yang sudah diketahui, dan hal yang belum diketahui agar dapat dilakukan suatu tindakan penyempurnaan. Adapun realisasinya adalah; pertanyaan langsung tentang apa-apa yang diperolehnya hari itu, catatan dan jurnal di buku siswa, kesan dan saran siswa mengenai pembelajaran pada hari itu, diskusi dan hasil karya.

7. Penilain Otentik, prosedur penilaian yang menunjukkan kemampuan (pengetahuan, ketrampilan sikap) siswa secara nyata. Penekanan penilaian otentik adalah pada; pembelajaran seharusnya membantu siswa agar mampu mempelajari sesuatu, bukan pada diperolehnya informasi di akhir periode, kemajuan belajar dinilai tidak hanya hasil tetapi lebih pada prosesnya dengan berbagai cara, menilai pengetahuan dan ketrampilan yang diperoleh siswa. 


\section{Rumusan Masalah}

Dengan latar belakang yang dipaparkan diatas maka dapat diambil bentuk rumusan masalah sebagai berikut :

1. Bagaimana metode Contextual Teaching and Learning( CTL ) digunakanatau diterapkan dalam materi pembelajaran BEGOING TO vs WILLdi SMK NEGERI 2 MANADO ?

2. Keuntungan apa yang didapati dalam menerapkan metode Contextual Teaching and Learning ( CTL ) pada materi pembelajaranBE GOING TO vs WILLbagi peserta didik, dan bagi pengajar dalam hal ini guru yang ada di SMK NEGERI 2 MANADO?

\section{Tujuan Penelitian}

Yang menjadi tujuan penelitian ini adalah :

1. Agar dapat mendeskripsikan dan menerapkan metode Contextual Teaching and Learning( CTL ) dalam pembelajaran BE GOING TO dan WILL di SMK NEGERI 2 MANADO.

2. Menjelaskan dan Menggunakan metode pembelajaran Contextual Teaching and Learning ( CTL ) dalam bentuk ekspresi Future Tense BE GOING TO dan WILL agar dapat mempermudah pemahaman dari peserta didik dalam mempelajari materi ajar dan bahkan mampu menciptakan situasi pembelajaran yang menyenangkan bagi peserta didik dan guru sebagai pengajar di SMK NEGERI 2 MANADO.

\section{Manfaat Penelitian}

1. Secara Teoretis

Bentuk hasil penelitian ini memiliki manfaat dalam pengembangan mutu pembelajaran Bahasa Inggris yang berbasiskan Contextual Teaching and Learning ( CTL ) lebih khususnya dalam penerapan pembelajaran BE GOING TO vs WILL di tingkat satuan pendidikan menengah kejuruan.

2. Secara Praktis 
Metode Contextual Teaching and Learning ( CTL ) memudahkan bagi pengajar dalam hal ini bagi guru ketika menerapkan materi ajar melalui model pembelajaran yang menyenangkan.

Dapat memberi kemudahan pula bagi peserta didik dalam menerima materi yang selalu dikaitkan dengan berdasarkan lingkungan sekitar dan pengalaman pribadinya.

\section{Kerangka Teoretis}

Mempelajari suatu bahasa tidak akan pernah lepas dari struktur bahasa itu sendiri. Struktur atau aturan bahasa menjadi bagian inti yang utama ketika akan memahami dan mendalaminya. Struktur akan berkait erat dengan Grammar atau aturan dan tata bahasa. Dalam mengawali buku yangberjudul English Grammar Jefrrey Coghill and StacyMagendanz, dua orang pendiri Perpustakaan dan Kampus McNeese State University di Lake Charles, Los Angeles (2003:xvi) mendefinisikan grammar sebagai berikut:

"The grammar of a language is the set of rules that govern its structure. Grammar determines how words are arranged to form meaningful units"( Grammar sebuah bahasa adalah satu kumpulan aturan yang menata bagian susunannya. Grammar menentukan bagaimana kata-kata disusun dalam membentuk unit-unit bahasa yang bermakna.").Lebih ekstrim lagi, pakar kenamaan tentang Grammar si Greenbaum (1996:25) mengartikan Grammar seperti di bawah ini:

"In the concrete sense of the word grammar, a grammar is a book of one or more volumes. We of course also use grammar for the contents of the book. When we compare grammars for their coverage

and accuracy, we are referring to the contents of the book: a grammar is a book on grammar, just as a history is a book on history."("Menurut makna konkrit kata Grammar, grammar adalah sebuah buku yang berisi satu volume atau lebih.Kita juga tentu mengartikan grammar sebagai isi sebuah buku. Ketika kita membandingkan grammar dengan bahasan dan kebebenarannya, kita tentu mengacu pada isi dari sebuah buku: jadi Grammar adalah sebuah buku tentang grammar, seperti halnya sejarah adalah sebuah buku tentang sejarah.").Hubungan yang sangat kuat juga dikaitkan dengan bentuk yang 
mengekspresikan Future Time :BE GOING TO dan WILL. Yang mana dijelaskan "Will and be going to usually give the same meaning, but sometimes they express different meanings" from Betty Schrampfer Azar ( $1993: 47$ ).

Ketika kita mempunyai niat untuk mengerjakan sesuatu di masa depan maka kita membutuhkan suatu ungkapan untuk meyakinkan bahwa kita mampu untuk melakukannya. Dalam bahasa inggris kita biasanya menggunakan kata will yang berarti "akan" dimana artinya sesuatu yang berniat dilakukan oleh seseorang di masa depan.

\section{Jenis-jenis kalimat menggunakan kata "will "}

\section{Kata Will dalam Simple Future}

Digunakan untuk mengungkapkan sesuatu yang terjadi di masa depan. Keterangan waktu yang biasa digunakan pada Simple Futurea dalah tomorrow, tonight, next, soon, later and etc. Rumus penulisannya adalah :

\section{(+) S+will/be going to+V1}

(-) S+will not/be not going to+V1

(?) Will/be+S(going to)+V1

(Nominal) S+will+be+Complement

\section{Kata will untuk prediksi}

Digunakan sebagai ungkapan untuk menyatakan prediksi. Rumus penulisannya sama dengan simple future, tetapi diberikan Supporting Sentence yang meyakinkan.

\section{Kata will untuk kesediaan}

Digunakan sebagai ungkapan untuk menyatakan kesediaan. Rumus penulisannya sama dengan simple future yakni S+will+V1.

\section{Kata will untuk kejadian di masa depan dengan Adverbial Clause of Time}


Digunakan sebagai ungkapan untuk menyatakan kejadian di masa depan dengan Adverbial Clause of Time yang bisa diletakkan di awal maupun di akhir kalimat. Rumus penulisannya sama dengan simple future, tetapi diberi keterangan adverbial clause of time.

\section{Kata will untuk Conditional Sentence type 1}

Digunakan untuk mengungkapkan pengandaian yang nungkin terjadi di masa sekarang. Rumus penulisannya adalah Present Future if Present Tense atau kebalikannya.

Masih dalam Betty Schrampfer Azar ( 1993 : 49 - 51 ). :

\section{BENTUK - BENTUK DENGAN WILL}

\begin{tabular}{|l|l|l|}
\hline \multirow{2}{*}{ CONTRACTIONS } & $\begin{array}{l}\text { I'll, you'll, she'll, he'll, } \\
\text { it'll. We'll, they'll }\end{array}$ & $\begin{array}{l}\text { Will is usually contracted } \\
\text { with pronouns in both speech } \\
\text { and informal writing. }\end{array}$ \\
\cline { 2 - 3 } & $\begin{array}{l}\text { Bob + will = Bob'll } \\
\text { The teacher + will = the } \\
\text { teacher 'll }\end{array}$ & $\begin{array}{l}\text { Will is usually contracted } \\
\text { with nouns in speech, but } \\
\text { usually not in writing. }\end{array}$ \\
\hline
\end{tabular}

\section{MENGGUNAKAN PROBABLY DENGAN WILL}

(a) Ann will probably go to park tomorrow.

(b) Bob probably won't go to the park tomorrow.

(c) FORMAL : Bob will probably not go to the park tomorrow.

People often use probably with will.
Probably comes between will and
the main verb as in (a). in a negative
sentence, probably comes in front
of won't as in (b) or more formally,
between will and not, as in (c).

People often use probably with will.

Probably comes between will and the main verb as in (a). in a negative sentence, probably comes in front between will and not, as in (c). 


\section{BE GOING TO vs WILL}

\begin{tabular}{|c|c|}
\hline $\begin{array}{l}\text { (a) She is going to succeed because the } \\
\text { works hard. } \\
\text { (b) She will succeed because she works } \\
\text { hard. } \\
\text { (c) He is going to carried some books } \\
\text { in this class. } \\
\text { (d) He will carried some books in this } \\
\text { class. } \\
\text { (e) I am going to made assignments for } \\
\text { my uncle John. } \\
\text { (f) I will made some assignments for } \\
\text { my uncle John. }\end{array}$ & $\begin{array}{l}\text { Be going to and will are the same } \\
\text { when they are used to make } \\
\text { predictions about the future. (a) and } \\
\text { (b) have the same meaning. }\end{array}$ \\
\hline $\begin{array}{l}\text { ( c) I bought some wood because I am } \\
\text { going to build a bookcase for my } \\
\text { apartment. } \\
\text { ( d ) She cried in the rain because of } \\
\text { her problems } \\
\text { (e ) My friend Rida talked on the } \\
\text { telephone about the problem with } \\
\text { her close friend. }\end{array}$ & $\begin{array}{l}\text { Be going to ( but not will ) is used to } \\
\text { express a preconceived plan. In ( } \mathrm{c} \text { ) : } \\
\text { The speaker is planning to build a } \\
\text { bookcase. }\end{array}$ \\
\hline $\begin{array}{l}\text { ( d ) This car is too heavy for you to } \\
\text { carry alone. I'll help you. } \\
\text { ( e ) My mother's bag is red. She'll } \\
\text { give it to you later. }\end{array}$ & $\begin{array}{l}\text { Will ( but not going to ) is used to } \\
\text { volunteer or express willingness. In ( } \\
\text { d ): The speaker is happy to help. }\end{array}$ \\
\hline
\end{tabular}


Melihat secara nyata bentuk penjelasan yang ada di atas maka untuk mengaplikasikan materi pembelajaran ini sebagai penerapannya dengan jelas , metode Contextual Teaching and Learning ( CTL ) akan berperan penting bagi pengajar dan peserta didik. Penulis mengambil teori dari Nurhadi dalam Sugianto (2007) CTL ( Contextual Teaching and Learning ) adalah konsep belajar yang mendorong guru untuk menghubungkan antara materi yang diajarkan dan situasi dunia nyata peserta didik. Hal ini juga dikarenakan sesuai dengan masalah yang ditampilkan dalam konteks penelitian ini.

\section{Metodologi}

Dalam metodologi penelitian ini, pendekatan yang digunakan adalah pendekatan kuantitatif. Pendekatan kualitatif sendiri digunakan untuk dapat mendeskripsikan penerapan metode CTL dalam pembelajaran yang mengekspresikan bentuk Future Time :BE GOING TO dan WILL bagi peserta didik kelas XI SMK NEGERI 2 MANADO.

Studi kualitatif juga merupakan metode yang diarahkan tentang riset yang besifat deskriptif dan cenderung menggunakan analisis, dapat dilihat juga proses dan makna lebih ditonjolkan dalam penelitian ini dengan berlandaskan teori dimanfaatkan sebagai pemandu agar focus penelitian sesuai dengan fakta di lapangan.

Oleh David Williams (1995) seperti yang dikutip Moleong (2007:5) mengemukakan bahwa penelitian kualitatif adalah pengumpulan data pada suatu latar alamiah, dengan menggunakan metode alamiah, dan dilakukan oleh orang atau peneliti yang tertarik secara alamiah.Selanjutnya penelitian kualitatif menurut Moleong (2007:6) adalah penelitian yang bermaksud untuk memahami fenomena tentang apa yang dialami oleh subjek penelitian misalnya perilaku, persepsi, motivasi, tindakan, dll., secara holistik, dan dengan cara deskripsi dalam bentuk kata-kata dan bahasa, pada suatu konteks khusus yang alamiah dan dengan memanfaatkan berbagai metode alamiah.

Data dalam penelitian kualitatif kebanyakan diperoleh dari sumber manusia atau human resources, melalui observasi dan wawancara. Akan tetapi ada pula sumber bukan manusia, non human resources, diantaranya dokumen, 
foto dan bahan statistik. Studi dokumen yang dilakukan oleh para peneliti kualitatif, posisinya dapat dipandang sebagai "nara sumber" yang dapat menjawab pertanyaan; "Apa tujuan dokumen itu ditulis?; Apa latar belakangnya?; Apa yang dapat dikatakan dokumen itu kepada peneliti?; Dalam keadaan apa dokumen itu ditulis?; Untuk siapa?; dan sebagainya.(Nasution, 2003; 86).

Menurut Sugiyono $(2008 ; 83)$ studi dokumen merupakan pelengkap dari penggunaan metode obsevasi dan wawancara dalam penelitian kualitatif. Bahkan kredibilitas hasil penelitian kualitatif ini akan semakin tinggi jika melibatkan / menggunakan studi dokumen ini dalam metode penelitian kualitatifnya hal senada diungkapkan Bogdan (seperti dikutip Sugiyono) “ in most tradition of qualitative research, the phrase personal document is used broadly lo refer to any first person narrative produce by an individual which describes his or her own actions, experience, and beliefs".

Ada beberapa keuntungan dari penggunaan studi dokumen dalam penelitian kualitatif, seperti yang dikemukakan Nasution (2003; 85); a) Bahan dokumenter itu telah ada, telah tersedia, dan siap pakai; b) penggunaan bahan ini tidak meminta biaya, hanya memerlukan waktu untuk mempelajarinya; c) banyak yang dapat ditimba pengetahuan dari bahan itu bila dianalisis dengan cermat, yang berguna bagi penelitian yang dijalankan; d) dapat memberikan latar belakang yang lebih luas mengenai pokok penelitian; e) dapat dijadikan bahan triangulasi untuk mengecek kesesuaian data; dan f) merupakan bahan utama dalam penelitian historis.

\section{Lokasi dan Waktu Penelitian}

Lokasi dari penelitian ini yaitu Sekolah Menengah Kejuruan Negeri 2 Manado. Jangka waktu penelitian ini yaitu 4 bulan yang sudah dilakukan sejak semester ketiga ditahun ajaran 2017 / 2018 berjalan yaitu bulan Agustus 2017 sampai pada bulan November 2017. Yang waktu pelaksanaannya dilakukan secara bertahap yakni :

1. Masuk pada tahap Orientasi, dilakukan dalam dua kali pertemuan pertama

2. Tahap Implementasi, dilakukan selama 3 bulan, dan 
3. Tahap Evaluasi, yang pelaksanaannya pada minggu ke - 3 bulan Oktober dan minggu ke - 3 bulan November.

\section{Sumber Data}

Sumber data dari penelitian ini diambil dari Kepala Sekolah selaku pimpinan sekolah, wali kelas, guru mata pelajaran dan peserta didik kelas XI Jurusan Multi Media SMK NEGERI 2 MANADO yang berjumlah 17 orang.

\section{Metode dan Tekhnik Pengumpulan Data}

Sugiono ( 2008 : 63 ) ada empat macam tekhnik pengumpulan data yaitu observasi, wawancara, dokumentasi, dan gabungan / triangulasi. Triangulasi merupakan cara pemeriksaan keabsahan data yang paling umum digunakan. Cara ini dilakukan dengan memanfaatkan sesuatu yang lain diluar data untuk pengecekan atau sebagai pembanding terhadap data itu. Dalam kaitan ini Patton (dalam Sutopo, 2006: 92) menjelaskan teknik triangulasi yang dapat digunakan. Teknik triangulasi yang dapat digunakan menurut Patton meliputi: a) triangulasi data; b) triangulasi peneliti; c) triangulasi metodologis; d) tringulasi teoretis.

Dalam teknik pengumpulan data, triangulasi diartikan sebagai teknik pengumpulan data yang bersifat menggabungkan dari berbagai teknik pengumpulan data dan sumber data yang telah ada.Bila peneliti melakukan pengumpulan data dengan triangulasi, maka sebenarnya peneliti mengumpulkan data sekaligus menguji kredibilitas data, yaitu mengecek kredibilitas data dengan berbagai teknik pengumpulan data dan berbagai sumber data.

\section{a. Triangulasi Data}

Teknik triangulasi data dapat disebut juga triangulasi sumber. Cara ini mengarahkan peneliti agar di dalam mengumpulkan data, ia berusaha menggunakan berbagai sumber yang ada. Teknik triangulasi model ini dapat digambarkan sebagai berikut:

Wawancara Informan
Data
Content Analysis
Dokumen 
b. Triangulasi Peneliti

Triangulasi peneliti adalah hasil penelitian baik yang berupa data maupun kesimpulan mengenai bagian tertentu atau keseluruhannya dapat diuji oleh peneliti lain (Sutopo, 2006: 93). Triangulasi peneliti dapat dilakukan dengan menyelenggarakan diskusi atau melibatkan beberapa peneliti yang memiliki pengetahuan yang mencukupi. Triangulasi ini dapat digambarkan kedalam bagan berikut:

\section{Peneliti 1}

Data Peneliti 2 Data

Peneliti 3

Gambar 2 Model Triangulasi Peneliti

c. Triangulasi Metodologis

Teknik triangulasi metode digunakan dengan cara mengumpulkan data sejenis tetapi menggunakan metode yang berbeda (Patton dalam Sutopo, 2006: 93). Teknik triangulasi ini dapat digambarkan sebagai berikut:

Kuesioner
Data
Wawancara
Sumber Data

Observasi

Gambar 3 Model Triangulasi Metodologis 


\section{d. Triangulasi Teoretis}

Triangulasi jenis ini dilakukan oleh peneliti dengan menggunakan perspektif lebih dari satu teori dalam membahas permasalahan yang dikaji (Patton dalam Sutopo, 2006: 98).Oleh karena itu, dalam melakukan jenis triangulasi ini, peneliti harus memahami teori-teori yang digunakan dan keterkaitannya dengan permasalahan yang diteliti sehinngga mampu menghasilkan simpulan yang mantap. Teknik triangulasi model ini dapat digambarkan sebagai beikut :

\section{Teori 1}

Makna Teori $2 \quad$ Konteks / Peristiwa

Teori 3

\section{Gambar 4 Model Triangulasi Teoritis}

Dari empat bentuk teknik tringulasi yang ada, peneliti hanya menggunakan Teknik triangulasi metode dengan cara mengumpulkan data sejenis tetapi menggunakan metode yang berbeda (Patton dalam Sutopo, 2006: 93). yang dapat digambarkan kembali :

Kuesioner

Data Wawara $\quad$ Sumber Data

Observasi

\section{Model Triangulasi Metodologis}

\section{Teknik Analisis Data}

Bentuk penelitian ini menggunakan penelitian kualitatif dengan metode triangulasi metodologis. Pendekatan kualitatif adalah suatu proses penelitian dan pemahaman yang berdasarkan pada metodologi yang menyelidiki suatu fenomena sosial dan masalah manusia. Pada pendekatan ini, peneliti membuat suatu gambaran kompleks, meneliti kata-kata, laporan terinci dari pandangan responden, dan melakukan studi pada situasi yang alami (Cresswell, 1998: 15). Bogdan dan 
Taylor (Moleong,2007: 3) mengemukakan bahwa metodologi kualitatif merupakan prosedur penelitian yang menghasilkan data deskriptif berupa katakata tertulis maupun lisan dari orang-orang dan perilaku yang diamati. Sedangkan metode triangulasi sekali lagi dijelaskan yaitu merupakan metode dengan cara mengumpulkan data sejenis tetapi menggunakan metode yang berbeda (Patton dalam Sutopo, 2006: 93).Metode penelitian kualitatif Adalah metode yang lebih menekankan pada aspek pengukuran secara obyektif terhadap fenomena social. Untuk dapat melakukan pengukuran, setiap fenomena social di jabarkan kedalam beberapa komponen masalah, variable dan indicator. Setiap variable yang di tentukan di ukur dengan memberikan symbol - symbol angka yang berbeda beda sesuai dengan kategori informasi yang berkaitan dengan variable tersebut. Dengan menggunakan symbol - symbol angka tersebut, teknik perhitungan secara kuantitatif matematik dapat di lakukan sehingga dapat menghasilkan suatu kesimpulan yang belaku umum di dalam suatu parameter. Tujuan utama dati metodologi ini ialah menjelaskan suatu masalah tetapi menghasilkan generalisasi. Generalisasi ialah suatu kenyataan kebenaranyang terjadi dalam suatu realitas tentang suatu masalah yang di perkirakan akan berlaku pada suatu populasi tertentu ( Sumanto : 1995 )

Dalam bentuk penelitian ini analisis data yang disederhanakan melalui beberapa tahapan yakni tahapan pertama mengidentifikasi data yang diperoleh dari lapangan baik dengan cara wawancara, interview, observasi bahkan dokumentasi yang sumbernya dari buku, literature dan dokumen pembelajaran yan lainnya. Sedangkan pada tahapan kedua yakni mengklasifikasikan data yang ada dan disesuaikan dengan permasalahan dan tujuan dalam penelitian.

\section{Penggunaan Contextual Teaching and Learning pada Pembelajaran ( CTL ) yang mengekspresikan bentuk Future Time yaitu BE GOING TO dan WILL.}

Bentuk penggunaan data ini agar dapat mendeskripsikan penggunaan Contextual Teaching and Learning ( CTL ) dalam pembelajaran bahasa inggris 
yang berkaitan dengan bentuk pembelajaran yang mengekspresikan Future Time dalam hal ini BE GOING TO dan WILL. Dengan pemahaman bahwa menggunakan metode ini sungguh akan sangat membantu peserta didik dan pengajar dalam mendapatkan pemahaman materi yang lebih mendalam lagi bahkan lebih mempermudah dalam membentuk kalimat dengan pebedaannya masing - masing dalam hal ini BE GOING TO dan WILL dengan tepat pada penggunaannya juga. Penerapan metode ini dilakukan di dalam kelas di mana sebelum menerapkannya dilihat dulu perbandingan dengan menggunakan metode lain yangdipakai sebelumnya. Selesai dengan itu dilakukan bentuk pre test dengan tujuan mengetahui sudah sejauh mana pengetahuan dan pemahaman peserta didik dalam mempelajari ekspresi Future Time BEGOINGTO dan WILL, dan setelahnya dilakukanlah penerapan metode bentuk CTL.

\section{Hasil Penelitian}

Penggunaan Komponen Contextual Teaching and Learning CTL

Merupakan hal yang penting dalam penelitian sebelum melakukan tindakan penelitian itu sendiri adalaha baik untuk melakukan pengamatan sebagai observasi utama bagi sekolah termasuk di dalamnya kelas dan perangkat sekolah yang terkait seperti Pimpinan sekolah, Guru pengajar, wali kelas dan intinya peserta didik itu sendiri. Dengan melihat hasil observasi yang ada maka sangatlah perlu merubah paradigma dalam pola berpikir dengan menggunakan metode pembelajaran yang lama yang juga bisa dikatakan bentuk pembelajaran 'traditional method'yang biasa dilakukan dan diterapkan setiap pengajar. Olehnya salah satu cara yang dapat dilakukan guna memperbaiki hasil capaian belajar siswa yaitu dengan mengganti metode lama tersebut dengan metode Contextual Teaching and Learning yang sangat berpusat pada peserta didik.

\section{Kesimpulan dan Saran}

\section{$>$ Kesimpulan}

Pendekatan Kontekstual merupakan konsep belajar yang memudahkan guru mengaitkan antara materi yang diajarkan dengan situasi dunia nyata siswa dan 
mendorong siswa membuat hubungan antara pengetahuan yang dimilikinya dengan penerapannya dalam kehidupan sehari-hari.

Dengan penerapan dalam model pembelajaran yang menggunakan metode CTL maka dapatlah dilihat banyak keuntungan yang didapati oleh peserta didik dimana terdapat beragam aspek yang dapat digunakan dalam mencapai hasil pembelajaran yang baik. CTL sendiri menanamkan cara yang tepat yang melibatkan langsung dan mengaitkan pengalaman dalam dunia nyata dan bahkan ruang lingkup peserta didik; bahkan pembelajaran yang diberikan mampu mendorong siswa untuk boleh bekerja bersama dalam kelompok berbagi dan saling mengisi bahkan menciptakan suasana yang nyata dalam bekerja sama dengan yang lain guna tercapainya materi dan bahan ajar yang diberikan. Sedangkan bagi pengajar sendiri memudahkannya dalam mengaplikasikan bahan ajar yang akan diberikan sebagai materi di mana pusat pembelajaran yang menjadi inti sangat akan terfokus pada peserta didik, dengan kata lain semuanya hanya pada student centre .

$>\quad$ Metode penelitian kualitatif ini berisi tentang bahan prosedur dan strategi yang digunakan dalam riset, serta keputusan- keputusan yang dibuat tentang desain riset. Dalam penelitian kualitatif ini sering disebut metode penelitian naturalistik karena penelitiannya dilakukan pada kondisi yang alamiah (natural setting) karena data yang terkumpul dan analisisnya lebih bersifat kualitatif.

\section{Saran}

Untuk lebih meningkatkan kualitas pembelajaran yang ada khususnya untuk mata pelajaran bahasa Inggris sendiri yang lebih tepatnya tentang bentuk pembelajaran yang mengekspresikan Future Time yaitu BE GOING TO dan WILL. Sebenarnya ada banyak metode pembelajaran yang lain yang tidak kalah bagusnya untuk dapat ditawarkan bagi peserta didik, tetapi juga dapat disarankan adalah baik jika pengajat menerapkan metode pembelajaran Contextual Teaching and Learning

( CTL ) yang dapat dilihat hasil yang diperoleh di mana metode ini dapat menonjolkan kemampuan dalam system belajar peserta didik 


\section{DAFTAR PUSTAKA}

Amri, S dan Ahmadi. 2010. Proses Pembelajaran Kreatif dan Inovatif dalam kelas. Jakarta: PT. Prestasi Pustaka karya.

Betty Schrampfer Azar 1993. Fundamentals of English Grammar Second Edition. Jakarta:Binarupa Aksara

Coghill, Jeffrey and Stacy Magendanz. 2003. English Grammar. New York: Wiley Publishing, Inc.

Depdiknas ( 2002 ). Pendekatan Kontekstual ( Contextual Teaching and Learning ( CTL ). Jakarta : Direktorat Pendidikan Lanjutan Pertama, Direktorat Jenderal Pendidikan Dasar Menengah

Greenbaum, Sidney. 1996. English Grammar. Oxford University Press.

Leech, Geoffrey et all. 1982. English Grammar for Today. London: The Macmillan Press Ltd.

Nurhadi dan Agus Gerad.2003. Pembelajaran Konstektual dan Penerapannya dalam KBK.Universitas Negeri Malang. Surabaya.

Moleong, Lexy J.2007. Metodologi Penelitian Kualitatif. Bandung: Remaja Rosda Karya.

Sugiyono, 2008. Metode Penelitian kuantitatife, Kualitatife, dan R \& D. Bandung: ALFABETA.

Sutopo, HB. 2006, Metode Penelitian Kualitatif, Surakarta: UNS Press.

Swan, Michael. 2005. Practical English Usage: $3^{\text {rd }}$ Edition. Oxford University Press.

Drs.Sumanto.M.A. , 1995 , Metodologi Penelitian Sosial Dan Pendidikan, Yogyakarta : Andi Offset.

http://www.eurekapendidikan.com/2014/10/pengertian-pendekatan-

kontesktual.html

Disalin dan Dipublikasikan melalui Eureka Pendidikan 
Trianto (2008 : 13-15) Pendekatan kontekstual mendasarkan diri pada kecenderungan pemikiran tentangbelajar

Source: http://www.eurekapendidikan.com/2014/10/pengertian-pendekatankontesktual.html Disalin dan Dipublikasikan melalui Eureka Pendidikan

:http://www.englishindo.com/2011/04/definisi-grammar-menurut-ahligrammar.html\#ixzz4y5U1no9E 